\title{
ANALISIS PERBEDAAN MORFOLOGI DAN KELIMPAHAN KARANG PADA DAERAH RATAAN TERUMBU (Reef Flate) DENGAN DAERAH TUBIR (Reef Slope) DI PULAU PANJANG, JEPARA
}

\author{
Kiai Agoes Septyadi, Niniek Widyorini, Ruswahyuni *) \\ Jurusan Perikanan, Fakultas Perikanan dan Ilmu Kelautan, Universitas Diponegoro \\ J1. Prof. H. Soedharto, SH, Tembalang Semarang. 50275 Telp/Fax (024) 7474698
}

\begin{abstract}
Abstrak
Pulau Panjang merupakan kawasan wisata di Jepara yang memiliki potensi salah satunya adalah ekosistem terumbu karang. Ekosistem terumbu karang mempunyai fungsi ekologis yaitu sebagai habitat untuk berkembang biak, mencari makan dan berlindung bagi biota lain. Terumbu karang juga mempunyai fungsi melindungi pantai dari hempasan ombak dan arus laut. Selain itu keindahan alam laut dan terumbu karang sendiri dapat meningkatkan taraf hidup masyarakat sebagai daerah pariwisata bahari.

Tujuan dari penelitian ini adalah untuk mengetahui perbedaan morfologi karang pada zona rataan (reef flat) dengan terumbu karang daerah tubir (reef slope) di perairan pulau Panjang, Jepara. Dan mengetahui kelimpahan terumbu karang pada zona rataan (reef flat) dan terumbu karang pada zona tubir (reef slope) di perairan pulau Panjang, jepara. Metode yang digunakan dalam penelitian ini adalah metode survei. Dimana metode yang digunakan tergolong dalam metode survei yang bersifat deskriptif. Metode yang digunakan pada pengambilan data adalah Line Intercept Transect (LIT). Penelitian dilakukan pada dua lokasi yaitu daerah rataan terumbu dan daerah tubir. Panjang line transek adalah $10 \mathrm{~m}$, di letakkan sejajar garis pantai, transek yang digunakan di daerah rataan terumbu sebanyak 3 line dan daerah tubir sebanyak 3 line. Jarak antara line dimasing-masing lokasi sampling $5 \mathrm{~m}$.

Hasil penelitian jenis karang yang ditemukan di rataan terumbu dan tubir yaitu adalah jenis Porites sp., Acropora sp., Echinopora sp., Turbinaria sp., Goniastrea sp., Pavona sp., Favites sp., Leptoseries sp., Pectinia sp., dan Goniopora sp. Prosentase penutupan karang hidup tertinggi di rataan terumbu yaitu jenis Porites sp. 26,73\% , Goniastrea sp. 4,10\% dan Acropora sp 3,67\%. Sedangkan presentase penutupan karang hidup tertinggi di tubir yaitu jenis Porites sp. 35,67\%, Echinopora sp. 6,50\% dan Acropora sp. 6,33\%. Nilai prosentase penutupan karang hidup di daerah rataan terumbu sebesar 36,40\% yang termasuk dalam kategori sedang. Sedangkan nilai prosentase penutupan karang hidup di tubir sebesar 65,50\% termasuk kategori baik. Pada rataan terdapat jenis morfologi Acropora yaitu jenis Acropora Branching (ACB) sebesar 3,67\%, sedangkan pada tubir sebesar 6,33\%. Jenis morfologi yaitu jenis Acropora terdapat satu jenis yaitu Acropora Branching (ACB), Baik daerah rataan dan tubir. Sedangkan untuk non Acropora yang paling banyak adalah jenis Coral Encrusting (CE) baik pada rataan dan tubir.
\end{abstract}

Kata Kunci : Kelimpahan Karang, Daerah Rataan, Tubir dan Morfologi Karang, Pulau panjang

\begin{abstract}
Pulau Panjang is an area of tourism in jepara that has the potential one of them is an ecosystem coral reefs. A coral reef ecosystems has ecological functions, namely as the habitat to breed, search for food and shelter for the other biologic. Coral reefs also have a function protect the coast from lacing of waves and of the ocean currents. Besides natural beauty of the sea and coral reefs own can improve the living standards of people as a nautical tourism.

The purpose of this research is to tell the difference of morphology of the coral on reef flat areas ( reef flat) with the reef slope areas (reef slope) in Pulau Panjang, jepara. And knowing abundance of coral reef on reefflat areas (reef flat) and coral reef slope areas (reef slope) in Pulau Panjang, jepara. Methods used in this research is method of surveying. Actually, methods used characterizes method of surveying that is descriptive. Methods used in taking data is Line InterceptTtransect ( LIT ). Research carried on two spots was station A (Reef Flat) and station B (Reef Slope). The line's long zize is $10 \mathrm{~m}$, put in parallel along the coast, line used in the reef flat as much as three line and reef slope about three line. The distance between line each other location is $5 \mathrm{~m}$.

species of coral found in the reef flat and reef slope i.e. reef flat is the kind of Porites sp, Acropora sp, Echinopora sp, Turbinaria sp, Goniastrea sp, Pavona sp, Favites sp, Leptoseries sp, Pectinia sp, Goniopora sp. Closure of the highest percentage of living coral in reefflat is Porites sp 26,73\% Goniastrea sp 4, 10\% and Acropora sp 3.67\%. While the closing of the highest percentage of living coral in the reef slope i.e. the species of Porites sp 35,67 $\%$, Echinopora sp 6.50\% and Acropora sp, 6,33\%. The value of a percentage of living coral in an area closure reef flat reefs is 36,40\% included in the category of medium. While the value of the percentage of living coral on the closure of reef slope 65,50\% includes categories good. Only one Acropora morfology in reef flat and reef slope, its Acropora Branching (ACB). whereas for non-Acropora most exist is Coral Encrusting (CE) in both spot of reef flat and reef slope.
\end{abstract}

Key Word: Abundance of coral, Reef Flat, Reef slope, and Morfology of Coral, Pulau panjang. 


\section{JOURNAL OF MANAGEMENT OF AQUATIC RESOURCES}

Volume 2, Nomor 3, Tahun 2013, Halaman 258-264

Online di : http://ejournal-s1.undip.ac.id/index.php/maquares

\section{PENDAHULUAN}

Pulau Panjang merupakan kawasan wisata di Jepara yang memiliki potensi salah satunya adalah ekosistem terumbu karang. Ekosistem terumbu karang mempunyai fungsi ekologis yaitu sebagai habitat untuk berkembang biak, mencari makan dan berlindung bagi biota lain. Terumbu karang juga mempunyai fungsi melindungi pantai dari hempasan ombak dan arus laut. Selain itu keindahan alam laut dan terumbu karang sendiri dapat meningkatkan taraf hidup masyarakat sebagai daerah pariwisata bahari (Nybakken, 1992).

Terumbu karang merupakan asosiasi organisme yang kompleks yang mempunyai sejumlah tipe habitat yang berbeda-beda. Penggolongan habitat secara geomorfologi berupa zona-zona terumbu seperti rataan terumbu, puncak terumbu, dan tubir, yang didalamnya memiliki karakteristik beragam dan apabila mendapat tekanan terhadap lingkungan akan memberikan respon yang beragam pula (COREMAP, 2006).

Terumbu karang memiliki nilai estetika bawah air yang berpotensi sebagai objek wisata bahari, misalnya untuk snorkeling dan selam. Sehingga dirasakan perlu adanya suatu penelitian untuk mengungkap potensi bahari pulau Panjang, khususnya yang terdapat pada ekosistem terumbu karang.

Ekosistem terumbu karang memiliki fungsi yang bermanfaat sebagai habitat berbagai jenis biota laut, seperti ikan dan invertebrata. Sehingga Keadaan terumbu karang menentukan kelimpahan dan keanekaragaman biota yang hidup di ekosistemnya. Adanya kegiatan pariwisata dan penangkapan ikan secara ilegal dengan menggunakan Potasium atau bom ikan diduga telah mempengaruhi keberadaan terumbu karang dan organisme yang berasosiasi di dalamnya.

Suatu pulau biasanya dikelilingi oleh karang tepi (fringing reef), paparan terumbunya landai yang terdiri dari zona-zona terumbu seperti rataan terumbu (reef flat), puncak terumbu (reef crest), dan tubir (reef slope). Begitu pula pada pulau Panjang yang memiliki potensi terumbu karang yang harus tetap dijaga demi kelestarian.

Tujuan dari penelitian ini untuk mengetahui perbedaan morfologi karang pada zona rataan (reef flat) dengan terumbu karang daerah tubir (reef slope) dan mengetahui kelimpahan terumbu karang pada zona rataan (reef flat) dan terumbu karang pada zona tubir (reef slope) di perairan pulau Panjang, Jepara. Penelitian ini dilaksanakan di perairan pulau Panjang, Jepara pada bulan Juni - Juli 2012.

\section{MATERI DAN METODE}

\section{Materi Penelitian}

Bahan yang digunakan dalam kegiatan penelitian ini adalah hewan karang yang didapatkan dari lokasi, serta data variabel fisika dan kimia di lokasi tersebut di Pulau Panjang, Jepara.

\section{Metode Penelitian}

Sampling dilakukan di perairan pulau Panjang, adapun tahap kegiatan yang dilakukan adalah :

1. Sampling dilakukan disalah satu lokasi perairan pulau panjang pada daerah tubir dengan titik koordinat $52,5 \mathrm{BT}$ dan 33,6 LS dan daerah rataan dengan titik koordinat $110^{\circ} 37^{\prime} 47,7^{\prime \prime}$ BT dan $6^{\circ} 34^{\prime} 21,8^{\prime \prime}$ LS

2. Metode yang digunakan pada pengambilan data adalah Line Intercept Transect (LIT) (English et al., 1997). Disini Line Intercept Transect digunakan untuk mengukur penutupan karang. Penelitian dilakukan pada dua lokasi yaitu stasiun A (rataan terumbu) dan stasiun B (tubir). Panjang line transek adalah $10 \mathrm{~m}$, di letakkan sejajar garis pantai, transek yang digunakan di daerah rataan terumbu sebanyak 3 line dan daerah tubir sebanyak 3 line. Jarak antara line dimasing-masing lokasi sampling $5 \mathrm{~m}$.

3. Pengamatan dilakukan dengan cara mencatat jenis karang yang ditemukan disepanjang transek garis pada daerah rataan terumbu dan tubir.

4. Pada transek garis yang sudah ditentukan, dilakukan pengukuran terhadap ukuran panjang setiap individu karang yang dilewati transek garis.

5. Mencatat titik koordinat lokasi sampling pda rataan terumbu dan tubir dengan menggunakan Global Positioning System (GPS) .

Analisa Data

Untuk mengetahui penutupan karang perlu dilakukan pengolahan data, analisis yang dilakukan dapat dihitung dengan rumus sebagai berikut:

\section{Indeks keanekaragaman}

Indeks keanekaragaman menggambarkan keadaan populasi organisme secara matematis agar mepermudah menganalisa informasi jumlah individu masing-masing jenis pada suatu komunitas. Untuk itu dilakukan perhitungan dengan menggunakan persamaan dari Shanon-Wiener (Krebs, 1989) sebagai berikut:

$$
H^{\prime}=-\sum_{i=1}^{s} p^{i} \ln p^{i}
$$

Keterangan:
$\mathrm{H}^{\prime} \quad=$ Indeks keanekaragaman jenis
ni $\quad=$ Jumlah individu jenis $\mathrm{i}$
$\mathrm{S} \quad=$ Jumlah genus penyusun komunitas
$\mathrm{Pi} \quad=n i / \mathrm{N}$

$\mathrm{N} \quad=$ Jumlah total individu 


\section{Indeks keseragaman}

Indeks ini digunakan sebagai salah satu cara untuk mengetahui keseimbangan individu di dalam komunitas. Nilainya merupakan perbandingan antara nilai keanekaragaman dengan keanekaragaman maksimumnya. Rumus indeks keseragaman (Evennes) yang umumnya diberi simbol E, (Basmi, 2000). Dengan formula sebagai berikut :

$$
E=\frac{H^{\prime}}{H \max } \quad H_{\max }=L n S
$$

Keterangan :

$\mathrm{E} \quad=$ Indeks keseragaman

H' = Indeks keanekaragaman

$\mathrm{S} \quad=$ Jumlah genus penyusun komunitas

\section{Kelimpahan relatif}

Kelimpahan relatif dilakukan perhitungan dengan persamaan Odum (1971), sebagai berikut:

Dimana :

$$
K r=\frac{n i}{N} \times 100 \%
$$

$$
\begin{aligned}
& \mathrm{Kr}=\text { Kelimpahan relatif } \\
& \mathrm{ni}=\text { Jumlah individu spesies ke } \mathrm{i} \\
& \mathrm{N}=\text { Jumlah total individu }
\end{aligned}
$$

\section{Presentase penutupan karang (UNEP, 1993)}

Presentase penutupan karang dilakukan analisa data dengan menggunakan persamaan, yaitu :

Dimana:

$$
N i=\frac{L i}{L} \times 100 \%
$$

$\mathrm{Ni} \quad=$ Presentase penutupan koloni karang

$\mathrm{Li} \quad=$ Panjang koloni karang perpanjang transek garis $(\mathrm{cm})$

L $\quad=$ Panjang transek

Pembagian kategori penutupan karang sesuai dengan pendekatan Gomez dan Yap (1988), sebagai berikut :

$$
75-100 \% \quad \text { : Sangat baik }
$$

$50-74,9 \% \quad:$ Baik

$25-49,9 \% \quad:$ Sedang

$0-24,9 \% \quad:$ Rusak

\section{HASIL DAN PEMBAHASAN}

\section{HASIL}

Kondisi umum lokasi penelitian

Pulau Panjang adalah sebuah kepulauan yang terletak di sebelah utara kota jepara. Pulau Panjang ini memiliki daratan dengan luas wilayah $\pm 25000 \mathrm{~m}^{2}$, yang terletak antara $110^{\circ} 31^{\prime} 38^{\prime \prime} \mathrm{BT}$ sampai 110³5'58" BT dan 6³0'83" LS sampai 6³0'96" LS di wilayah Desa Ujung Batu Kecamatan Jepara Kota, Kabupaten Jepara dan berjarak 4 mill laut dari Laboratorium Pengembangan Wilayah Pantai (LPWP) Jepara (Pemda Kabupaten Jepara, 2000).

Lokasi penelitian di lakukan pada daerah rataan terumbu (reefflat) dan daerah tubir terumbu (reef slove) dengan membagi 3 line pada satu titik lokasi sampling tersebut. Lokasi sampling pada daerah rataan (reef flat terletak pada titik koordinat $6^{\circ} 34^{\prime} 35.96 " \mathrm{LS}$ dan $110^{\circ} 377^{\prime} 51.53 " \mathrm{BT}$, sedangkan untuk daerah tubir (reef slove) terletak pada titik koordinat 52,5 BT dan 33,6 LS. Sampling pertama dilakukan di daerah tubir pada pukul 10.00 dan dilanjutkan pada hari berikutnya sampling pada daerah rataan.

\section{Total penutupan karang dan persentase penutupan karang}

Persentase penutupan karang di daerah rataan dapat dilihat pada tabel berikut ini :

Tabel 1. jumlah penutupan karang hidup dan persentase penutupan karang hidup

\begin{tabular}{clcc}
\hline No & \multicolumn{1}{c}{ Jenis } & Panjang penutupan $(\mathrm{cm})$ & Persentase penutupan (\%) \\
\hline 1 & Porites $\mathrm{sp}$ & 802 & 26,73 \\
2 & Acropora $\mathrm{sp}$ & 110 & 3,67 \\
3 & Favites $\mathrm{sp}$ & 17 & 0,57 \\
4 & Goniopora $\mathrm{sp}$ & 11 & 0,37 \\
5 & Goniastrea $\mathrm{sp}$ & 123 & 4,10 \\
6 & Echinopora $\mathrm{sp}$ & 29 & 0,97 \\
\hline & jumlah & 1092 & 36,40 \\
\hline
\end{tabular}

Persentase penutupan karang di daerah tubir dapat dilihat pada tabel 2. 
Tabel 2. jumlah penutupan karang hidup dan persentase penutupan karang hidup

\begin{tabular}{clcc}
\hline No & \multicolumn{1}{c}{ Jenis } & Panjang penutupan $(\mathrm{cm})$ & Persentase penutupan (\%) \\
\hline 1 & Porites $\mathrm{sp}$ & 1070 & 35,67 \\
2 & Acropora $\mathrm{sp}$ & 190 & 6,33 \\
3 & Favites $\mathrm{sp}$ & 105 & 3,50 \\
4 & Goniastrea $\mathrm{sp}$ & 83 & 2,77 \\
5 & Echinopora $\mathrm{sp}$ & 195 & 6,50 \\
6 & Pavona $\mathrm{sp}$ & 99 & 3,30 \\
7 & Turbinaria $\mathrm{sp}$ & 83 & 2,77 \\
8 & Leptoseries $\mathrm{sp}$ & 98 & 3,27 \\
9 & Pectinia $\mathrm{sp}$ & 42 & 1,40 \\
\hline & Jumlah & 1965 & 65,50 \\
\hline
\end{tabular}

Dari data persentase pada tabel di atas dapat dilihat perbedaan persentase karang hidup antara rataan dan tubir yaitu pada grafik berikut.

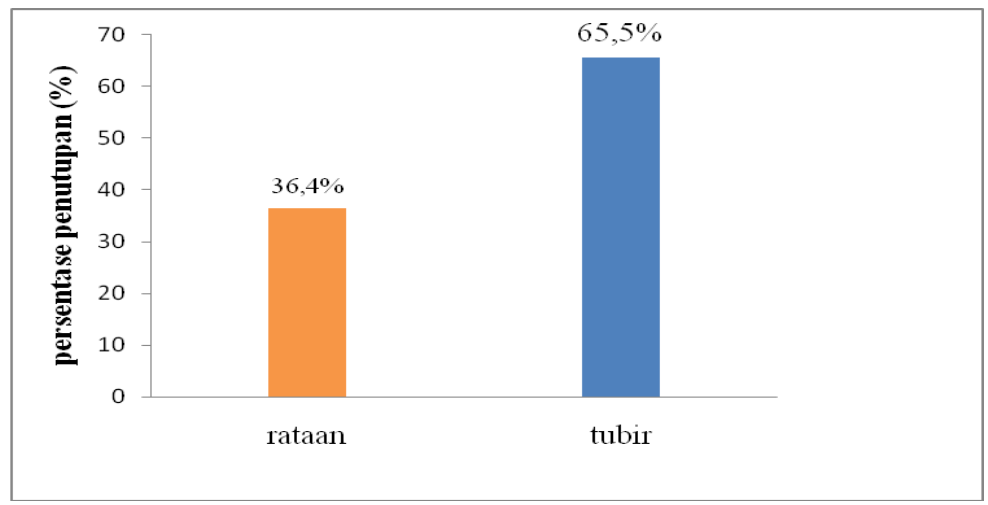

Gambar 1. Histogram persentase penutupan karang hidup

\section{Morfologi}

Pada rataan terdapat jenis morfologi Acropora yaitu jenis Acropora Branching (ACB) sebesar 3,67\%, sedangkan pada tubir sebesar 6,33\%. Pada daerah rataan maupun Tubir hanya terdapat satu jenis morfologi Acropora yaitu Acropora Branching (ACB). Sedangkan jenis morfologi karang lainnya adalah non-Acropora. Jenis non-Acropora yang ditemukan adalah Coral Encrusting (CE) sebesar 27,70\% pada rataan sedangkan pada tubir 45,47\%, Coral Massive (CM) sebesar 5,04\% pada rataan dan 6,27\% pada tubir, Coral Foliose (CF) sebesar 0\% pada rataan dan 6,04\% pada tubir, untuk Coral Submassive (CS) sebesar 0\% pada rataan sedangkan pada daerah tubir 1,40\%.

Berdasarkan persentase karang hidup sebesar $36,4 \%$ pada rataan dan $65 \%$ pada tubir diperoleh data persentase jenis morfologi karang sebagai berikut :

Tabel 3. Parameter Kualitas Air di Rataan dan Tubir

\begin{tabular}{lccc}
\hline \multirow{2}{*}{ Jenis Morfologi } & \multirow{2}{*}{ Kode Morfologi } & \multicolumn{2}{c}{ Stasiun } \\
\cline { 3 - 4 } & & $\mathrm{A}$ & $\mathrm{B}$ \\
\hline Acropora & ACB & 3,67 & 6,33 \\
Non-Acropora & CM & 27,70 & 45,47 \\
& CE & 5,04 & 6,27 \\
& CF & 0 & 6,04 \\
& CS & 0 & 1,40 \\
\hline
\end{tabular}

Indeks keanekaragaman (H') dan keseragaman (e) lamun

Indeks keanekaragaman dan indeks keseragaman karang daerah rataan dapat dilihat pada tabel berikut :

Tabel 4. Indeks Keanekaragaman dan Indeks Keseragaman

\begin{tabular}{clcc}
\hline No & \multicolumn{1}{c}{ Stasiun } & H' & E \\
\hline 1. & Rataan terumbu & 1,323 & 0,738 \\
2. & Tubir & 1,888 & 0,859 \\
\hline
\end{tabular}

Berdasarkan tabel tersebut dapat dilihat bahwa indeks keanekaragaman ( $\left.\mathrm{H}^{\prime}\right)$ pada rataan terumbu mempunyai nilai indeks keanekaragaman sebesar 1,323 dengan indeks keseragamannya sebesar 0,738 sedangkan pada daerah tubir keanekaragman (H') sebesar 1,888 dengan indeks keseragaman (e) sebesar 0,859. 


\section{Parameter kualitas air}

Berdasarkan hasil pengukuran kualitas air pada saat penelitian, didapatkan parameter kualitas air di rataan terumbu dan tubir tersaji pada tabel dibawah ini :

Tabel 5. Parameter Kualitas Air di Rataan Terumbu dan Tubir

\begin{tabular}{|c|c|c|c|c|}
\hline \multirow{2}{*}{ No } & \multirow{2}{*}{ Parameter } & \multicolumn{2}{|l|}{ Kisaran hasil } & \multirow{2}{*}{ Pustaka } \\
\hline & & Rataan & Tubir & \\
\hline 1. & Suhu & $29^{\circ} \mathrm{C}$ & $28^{0} \mathrm{C}$ & (Soekarno et. Al., 1983) \\
\hline 2. & Kec. Arus & $0,10 \mathrm{~m} / \mathrm{s}$ & $0,20 \mathrm{~m} / \mathrm{s}$ & (Supriharyono, 2009) \\
\hline 3. & Salinitas & $31 \%$ & $31 \%$ & (Nybakken,1992) \\
\hline 4. & $\mathrm{Ph}$ & 8 & 8 & 6.5-8.5 $\quad($ Effin, 2006$)$ \\
\hline 5. & Kecerahan & Sampai dasar & $2 \mathrm{~m}$ & $<15-20 \mathrm{~m}$ (Soekarno, 1995) \\
\hline 6 & Kedalaman & $0,7 \mathrm{~m}$ & $4 \mathrm{~m}$ & < $20 \mathrm{~m} \quad$ (Bakosurtanal, 1996) \\
\hline \multirow[t]{2}{*}{6.} & Substrat & \multirow{2}{*}{\multicolumn{2}{|c|}{$\begin{array}{l}\text { Karang hidup, Karang mati, } \\
\text { Pecahan karang, dan Pasir }\end{array}$}} & Karang hidup, Karang mati, (Azis, 1996) \\
\hline & dasar & & & Pecahan karang, dan Pasir \\
\hline
\end{tabular}

\section{PEMBAHASAN}

Jenis Karang pada rataan terumbu dan tubir

Dari hasil penelitian adapun jenis karang yang ditemukan di rataan terumbu dan tubir yaitu adalah jenis Porites sp., Acropora sp., Echinopora sp., Turbinaria sp., Goniastrea sp., Pavona sp., Favites sp., Leptoseries sp., Pectinia sp., dan Goniopora sp. Presentase penutupan karang hidup tertinggi di rataan terumbu yaitu jenis Porites sp. 26,73\% , Goniastrea sp. 4,10\% dan Acropora sp 3,67\%. Sedangkan presentase penutupan karang hidup tertinggi di tubir yaitu jenis Porites sp. 35,67\%, Echinopora sp. 6,50\% dan Acropora sp. 6,33\%. Karang Acropora sp, umumnya merupakan salah satu kelompok karang yang sangat dominan pada suatu perairan (Thamrin, 2006). Namun pada daerah rataan terumbu maupun daerah tubir perairan pulau Panjang banyak ditemukan jenis karang branching jenis Porites sp. yang mendominasi presentase penutupan karang. Menurut English et.al. (1994), jenis karang yang dominan disuatu habitat tergantung pada kondisi lingkungan atau habitat tempat karang tersebut hidup.

\section{Presentase penutupan karang}

Nilai presentase penutupan karang hidup di daerah rataan terumbu sebesar $36,40 \%$ yang termasuk dalam kategori sedang. Sedangkan nilai presentase penutupan karang hidup di tubir sebesar 65,50\% termasuk kategori baik. Pada daerah rataan terumbu mempunyai presentase penutupan karang hidup lebih kecil dari pada presentase penutupan karang hidup di daerah tubir. hal ini dipengaruhi posisi karang yang cukup dekat dengan pantai dan dermaga, dimana pada daerah rataan terumbu tersebut merupakan tempat lalu lintas kapal dan tambatan kapal nelayan maupun kapal angkut wisata pulau Panjang, kegiatan tersebut bisa merusak karang. Sedangkan pada daerah tubir sebaliknya jauh dari pantai dan jarang ada lalu lintas kapal walau pun ada tidak akan pengaruh karena daerah tubir lebih dalam dari daerah rataan yaitu dengan kedalaman 4 meter. Disini juga pengaruh arus berbeda antara arus pada rataan sebesar 0,10 m/s dan arus tubir $0,20 \mathrm{~m} / \mathrm{s}$, baik dari arus berasal dari lalu lintas kapal maupun angin dan pasang surut. Menurut Supriharyono (2007), menyatakan bahwa karang yang tumbuh atau teradaptasi pada perairan yang sedimennya tinggi cenderung berbentuk Folliose. Nontji (1987), menambahkan pertumbuhan karang juga akan lebih baik didaerah berarus atau bergelombang dibandingkan dengan perairan yang tenang.

\section{Indeks keanekaragaman (H') dan keseragaman (e) lamun}

Dari tabel 6 didapatkan nilai indeks keanekaragaman $\left(\mathrm{H}^{\prime}\right)$ pada daerah rataan sebesar 1,323, pada daerah tubir 1,888. Berdasarkan hasil analisis indeks keanekaragaman Menurut Odum (1971), bila $0<\mathrm{H}^{\prime} \leq 1$, maka keanekaragaman rendah, bila $1<\mathrm{H}^{\prime} \leq 2$. Dari nilai diatas menunjukkan bahwa nilai keanekaragaman antara rataan terumbu dan tubir termasuk dalam kategori keanekaragaman sedang. Menurut Poole (1974) dalam Suprapti et. al., (1993), keanekaragaman tidak hanya dilihat dari banyaknya jenis tapi juga dari penyebaran individu dalam tiap jenisnya dan tergantung dari kelimpahan individu dalam spesies.

Indeks keseragaman pada daerah rataan terumbu sebesar 0,738 dan untuk tubir sebesar 0,859, hal ini menunjukkan bahwa nilai keseragaman besar. Menurut Odum (1971) jika nilai indeks keseragaman mendekati 0, maka semakin kecil pula keseragaman biotanya sehingga dalam ekosistem tersebut ada kecenderungan terjadi dominasi spesies tertentu. Semakin besar nilai keseragaman yaitu mendekati 1, dapat diartikan bahwa dalam komunitas tersebut memiliki kelimpahan spesies yang sama atau dalam komunitas tersebut tidak didominasi oleh satu spesies dan dapat hidup secara merata, tetapi pertumbuhannya juga dipengaruhi oleh faktor kondisi lokasi tersebut.

\section{Morfologi Karang}

Pada stasiun A terdapat jenis morfologi Acropora yaitu jenis Acropora Branching (ACB) sebesar 3,67\%, sedangkan pada stasiun B sebesar 6,33\%. Pada stasiun A maupun stasiun B hanya terdapat satu jenis morfologi Acropora yaitu Acropora Branching (ACB). Sedangkan jenis morfologi karang lainnya adalah non-Acropora. Jenis non-Acropora yang ditemukan adalah Coral Massive (CM) sebesar 27,70\% pada stasiun A sedangkan pada stasiun B 45,47\%, Coral Encrusting (CE) sebesar 5,04\% pada stasiun A dan 6,27\% pada stasiun B, Coral Foliose (CF) sebesar 


\section{JOURNAL OF MANAGEMENT OF AQUATIC RESOURCES}

Volume 2, Nomor 3, Tahun 2013, Halaman 258-264

Online di : http://ejournal-s1.undip.ac.id/index.php/maquares

0\% pada stasiun A dan 6,04\% pada stasiun B, untuk Coral Submassive (CS) sebesar 0\% pada stasiun A sedangkan pada daerah stasiun B $1,40 \%$.

Dengan kondisi lingkungan di Pulau Panjang yang penuh kegiatan ekplorasi baik kegiatan penangkapan, lalu lintas kapal, pariwisata serta kegiatan manusia lainnya tentu sangat mengganggu kelangsungan hidup terumbu karang. Hanya jenis karang yang bisa tahan terhadap kondisi lingkungan seperti itu yang bisa tetap bertahan. Jenis karang tersebut adalah jenis karang Coral Massive (CM) karena karang ini termasuk dalam jenis karang padat (COREMAP, 2006)

\section{Parameter kualitas air di lokasi penelitian}

Dari pengamatan yang dilakukan pada lokasi penelitian seperti suhu, kecerahan, salinitas dan kecepatan arus, secara umum masih dalam kisaran normal yang bisa di toleransi oleh karang.

Hasil pengamatan di lapangan menunjukkan suhu perairan di lokasi penelitian daerah rataan sebesar $29^{\circ} \mathrm{C}$ dan daerah tubir $28^{\circ} \mathrm{C}$. Suhu perairan tersebut mendukung pertumbuhan dan kehidupan terumbu karang. Nybakken (1992) menyatakan bahwa karang tumbuh baik pada suhu 25 sampai $29{ }^{\circ} \mathrm{C}$ dan masih memiliki toleransi sampai suhu $40{ }^{\circ} \mathrm{C}$.

Salinitas perairan di lokasi penelitian daerah rataan didapatkan nilai sebesar $31 \%$ dan daerah tubir sama $31 \%$. Kisaran nilai masih sesuai untuk pertumbuhan dan perkembangan terumbu karang. Terumbu karang dapat tumbuh dan berkembang pada kisaran salinitas antara 30 sampai $36 \%$ (Nybakken 1992).

Nilai $\mathrm{pH}$ yang didapatkan pada saat penelitian yaitu sebesar 8 baik daerah rataan maupun tubir. kisaran tersebut masih dalam batas toleransi bagi terumbu karang untuk dapat tumbuh dan berkembang dengan baik. Terumbu karang umumnya tumbuh pada kisaran pH normal. Menurut Radisho (1994), pH yang menujang bagi kehidupan karang berkisar 6,5-8,5.

Kecepatan arus di lokasi penelitian adalah $0.10 \mathrm{~m} / \mathrm{s}$ pada daerah rataan dan $0.20 \mathrm{~m} / \mathrm{s}$ pada daerah tubir. Menurut Nontji (1987), bahwa pertumbuhan karang di tempat yang berarus lebih baik dibandingkan dengan perairan yang tenang. Ditambhakan oleh Nybakken (1992), adanya arus berfungsi untuk mensuplai nutrien dan oksigen yang sangat dibutuhkan oleh organisme di daerah terumbu karang.

Kecerahan berhubungan dengan penetrasi cahaya, kecerahan yang tinggi membuat penetrasi cahaya menjadi tinggi, faktor ini sangat berhubungan dengan ketersediaan cahaya dan tingkat kecerahan perairan. Kecerahan pada lokasi penelitian didapatkan kedalaman hingga dasar pada daerah rataan dan 2 meter di daerah tubir. Kecerahan menentukan intensitas cahaya matahari yang digunakan untuk proses fotosintesa. Menurut Sukarno (1995), Terumbu karang tidak dapat tumbuh dan berkembang pada kedalaman perairan lebih dari 50 meter. Pertumbuhan karang dibatasi oleh kedalaman yang berhubungan dengan penetrasi cahaya matahari yang masuk pada perairan.

\section{KESIMPULAN DAN SARAN}

\section{Kesimpulan}

Berdasarkan hasil penelitian yang diperoleh, maka dapat diambil kesimpulan sebagai berikut :

1. Keadaan jenis morfologi diantara staiun A dan stasiun B tidak terdapat perbedaan yang signifikan, untuk Acropora sama - sama terdapat satu jenis yaitu Acropora Branching (ACB) dengan nilai 3,67\% pada stasiun A dan 6,33\% di stasiun B. Sedangkan jenis morfologi yang paling banyak yaitu non-Acropora adalah jenis Coral Massive (CM) baik dari kedua stasiun, dengan nilai $27,70 \%$ pada stasiun A sedangkan pada stasiun B $45,47 \%$.

2. Kelimpahan karang hidup pada stasiun A yaitu $36,40 \%$ dikategorikan sedang dan $65,50 \%$ pada stasiun B termasuk kategori baik, dan keanekaragaman $\left(\mathrm{H}^{\prime}\right)$ pada stasiun A dan stasiun B termasuk keanekaragaman sedang dengan nilai 1,323 pada pada stasiun A dan 1,888 pada stasiun $\mathrm{B}$.

\section{Saran}

Perlu adanya penelitian lanjutan dengan jumlah titik lebih banyak agar lebih valid serta ada variabel pendukung lainnya dan perlu adanya sosialisasi kepada masyarakat mengenai arti pentingnya peranan karang dalam perairan sehingga kelestarian terumbu karang dapat terjaga dengan baik mengingat karang merupakan sumberdaya pesisir bermanfaat penting bagi ekosistem.

\section{DAFTAR PUSTAKA}

Basmi. J. 2000. Planktonologi : Planktonologi Sebagai Bioindikator Kualitas Perairan. Fakultas Perikanan dan Ilmu Kelautan Institut Pertanian Bogor.

COREMAP. 2006. Modul Biota Asosiasi dan Pola Interaksi Antar Spesies. COREMAP (Coral Reef Rehabilitation Management Program) Fase II. Kabupaten Selayar. Yayasan Lanra Link. Makassar.

English. S.C. Wilkinson and V Baker.1994. Survey Manual for Tropical marine Resources Australian of Marine Science. Townsville.

Krebs, C. J. 1989. Ecology The Eksperiment Analysis of Distribution and Abudance. Harper and Row Publisher, New York.

Nontji, A. 1987. Laut Nusantara. Djambatan. Jakarta.

Notoatmodjo, S. 2002. Metode Penelitian Kesehatan. Rineke Cipta, Jakarta, 207 hal. 
Nybakken, J. W. 1992. Biologi Laut. Suatu Pendekatan Ekologi. PT. Gramedia Pustaka Utama. Jakarta (Edisi Terjemahan).

Odum, E.P, 1971. Dasar-dasar ekologi. Edisi ketiga. Gadjah Mada University Press. Yogyakarta.

Radisho, 1994. Studi Karakteristik Hewan Karang Penyusun Ekosistem Terumbu Karang di Perairan Pulau Menjangan Besar dan Pulau Menjangan Kecil Zona Pemanfaatan Taman Nasional Laut Karimun Jawa, Jawa Tengah. Fakultas Perikanan dan Ilmu Kelautan. Institut Pertanian Bogor. Bogor (tidak dipublikasikan).

Suprapti, N. H. Sugondo, M. Hadi dan U. Tarwodjo. 1993. Studi Plankton di Sekitar Daerah PLTU. Semarang. 7 hlm. (tidak dipublikasikan)

Supriharyono. 2007. Pengelolaan Ekosistem Terumbu Karang. Penerbit. Djambatan. Jakarta.

Sukarno, R. 1995. Ekosistem Terumbu Karang dan Masalah Pengelolaannya. Materi Pendidikan dan Pelatihan Metodologi Penelitian Penentuan Kondisi Terumbu Karang. Pusat Penelitian dan Pegembangan Oseanologi LIPI dan Universitas Diponegoro. Semarang

Thamrin. 2006. Karang. Biologi Reproduksi dan Ekologi. Minamandiri Press. Pekanbaru.

UNEP. 1993. Pengamatan terumbu karang dalam perubahan. Ilmu Kelautan. Australia. 